\title{
The Aquaponic Ecosystem Using loT and IA Solutions
}

\author{
Ibtissame Ezzahoui, Faculty of Sciences Ben M'sick, University of Hassan II, Casablanca, Morocco \\ Rachida Ait Abdelhouahid, Faculty of Sciences Ben M'sick, University of Hassan II, Casablanca, Morocco \\ Khaoula Taji, Faculty of Sciences Ben M'sick, University of Hassan II, Casablanca, Morocco \\ Abdelaziz Marzak, Faculty of Sciences Ben M'sick, University of Hassan II, Casablanca, Morocco \\ Fadoua Ghanimi, Faculty of Sciences Ben M'sick, University of Hassan II, Casablanca, Morocco
}

\begin{abstract}
For solving the negative impact of the human evolution in earth, water, pollution, and quality of feed, a system of aquaponics is proposed to manage gardening and recover up to $90 \%$ of water used for plants. Aquaponics is a system that combines two names: aquaculture, which is the farming of fish, and hydroponic, which is the cultivation of plants (off-soil). On the other hand is the possibility of using the phytotron system. The objective of this solution is to collect performance measures, to control the watering conditions of plants (water level, temperature, humidity) with a cloud support and other possibilities offered by the internet of things (IoT). The paper aims to provide a smart solution integrating the phytotron solution in order to control the first part, which is the hydroponic, and the second part concerning the aquaculture in order to offer a smart environment.
\end{abstract}

\section{KEYWORDS}

Aquaculture, Aquaponic, Economic Benefits, Fish, Health Benefits, Internet of Things, Phytotron, Plants

\section{INTRODUCTION}

The world is becoming more and more connected, the idea behind the concept of the internet of things (IoT) was to help smart cities to take the maximum advantages of several technologies. Smart environment is a very important part that brings people together and their environment, the human evolution, this one impact all, beginning by environment (earth, water, pollution, quality of feed, etc.), and the technology (smart solutions, easy life, etc.). Carlos-Hernandez et al. (2018), they say the human population aggrandizes aggressively and need more and more mainly resources, such as: energy, water, food, and health service. Currently, the food production systems are enriching or adjusted for preparing the resources needed by the new society. This transformation effects the quality of water consequently the animals, plants, fish, and more them human at the outset. Among the solutions proposed to manage water consumption in agriculture is aquaponic. Aquaponic unites plants cultivation and fish farming in a closed ecological system, its mainstay is intelligible: Aerobic bacteria are using to convert the ammonia contained in the fish waste (urine and waste) at nutrients like nitrate that can be a source to the plant, as a result the purified water returns to the aquarium. It is defined as a mixed solution to supervise the environment with two processes: aquaculture and hydroponics. According to (FAO), in excess of 560 species of fish can be grown by this method. 
(Carlos-Hernandez, 2018). So, aquaponics systems have the ability to agreeing production from the specific source of nutrients a different vegetables and fish.

There are several advantages according to our needs, the aquaponics systems offer the possibility to grow small spaces in urban areas and a closed-circuit production with a fairly large water saving (according to sources $80 \%$ to $99 \%$ less water than the conventional method), moreover, the aboveground watering implies reduce the problem concerning plant diseases so more healthy food, for example, the chemical treatment and disinfecting agents are used limitedly or exclude, a better control growing because the controlling of temperature, $\mathrm{pH}$, water, and nutrient. Furthermore, very little maintenance and weeding compared to the conventional method so no more than 5 to 10 Maximum of minutes per day to check the correct operation and feed the fish.

Besides, aquaponic can be used, for example, as an educational tool for university students, who can be apprentice the different fish and plants in aquaponics, so integrate the student in a deep environment and offer him a rich and concrete experience in technology. The implantation of plants and the fish's rearing used in certain research laboratories such as biology, nutrition, etc. Moreover, even the medical plants intended for the biology laboratory to enrich the experiments and tests carried out by those laboratories. And finally, the possibility of having different models and types according to the space and the system can be installing regrouped or separated.

This paper is organized as follow, the second section is dedicated to present a balance of sheet of regarding existing of aquaponic solution regrouped in the related works section, the third part is dedicated to present the health and economic benefits of an aquaponic system, section four is dedicated to the presentation of our proposition of a smart aquaponic based on phytotron solution, and finally the last section consist to present the conclusion and perspectives of the paper at hand.

\section{RELATED WORKS}

This technique was presented from centuries ago, and in the least 30 years ago a specific study was based on technology. The difficulties are in the different nature of species and their adaptation in the Aquaponics environment. The several conditions most by in harmony and equilibrium like: biological, physicochemical. (Carlos-Hernandez, 2018).

Maintaining the correct functioning, i.e. water level, measuring nutrient levels, controlling the $\mathrm{pH}$ of the system, is easy to manage in small installations but with large structure it is necessary to have a global system based on IoT.

The research carried out in the field of aquaponic with IoT is varied, (Yanes et al, 2020), they say that Aquaponic is one of the agricultural methods to use as an alternative, based on aquaculture (fish farming) and hydroponics (cultivation of soil-free plants), according to the article, this technique demands to use water efficacy, not use pesticides (because fish) and contract the quantity used of fertilizers, all these requirement make aquaponic system green and sustainable.

This study aims to support the search for a commercial aquaponic solution, they introduce sensing, smart and IoT to supervise and check the correct functioning of its automated system. Several contributions that are beneficial to addition the fully and semi-automated systems in small aquaponics systems size by automation and manufacturing experts. The authors desire introduces on commercial level the automation in aquaponics by clarification the liaison between sensors and every parameter serves.

(Karimanzira et al. 2018), at this paper the need for intensive monitoring, control and management are designed to make the modern aquaponic system efficient. the Automation Pyramid (AP) represents the different data and characteristics of low-level information (Sensors, actuators,...) with its Supervisory Control and Data Acquisition (SCADA) is meant to help to make decisions for the production line, the Enterprise Resource Planning (ERP) that gives a global back office on the business activity at the data level (integrity and constant updating) By integrating the IoT techniques we offer relief and predictability in real time, as well as flexibility and easy adaptation to the different 
requirements of the company can be added to the Manufacturing Execution System (MES) that represents the production activity.

For (Lee et al. 2020), and in this study a system is proposed: a cloud-based Internet of things monitoring system in aquaponics in order to measure the different parameters such as: water temperature, water depth, dissolved oxygen, and $\mathrm{pH}$ value. With the presence of three infrared distance sensors at different heights in the aquarium to monitor fish group activity after several treatments the data are uploaded to ThingSpeak ${ }^{\mathrm{TM}}$, a cloud platform, through Wi-Fi. Its principle main are using the cloud-based programming of ThingSpeak ${ }^{\mathrm{TM}}$. For the data stored on the cloud, a real-time alarm system for indicating abnormalities is developed and a periodic regression analysis is conducted.

In next search, the researches present a succeed application in smart aquaponics system, (Kyaw et al. 2017), As new the rapid urbanization in Singapore over the low local food and land scarcity, so take the opportunity to combine fish farming and plant growing in the aquaponic system by developed a smart aquaponics system for monitoring and controlling water quality, fish feed and all of sensors and elements including in this system. They involve a web and mobile applications, cloud server furthermore a data acquisition and system rectification unit, alarm unit and central processing unit (Figure 1).

In aquaponic, the agricultural technique used are more distinct to the conventional farming techniques. With the integration of Internet of Things, they have more benefits correspond to traditional farming. The negative impact of the human life in Indonesia affects the number of hectares of land and create in the next years a crisis in agricultural land. (Vernandhes et al,2017), propose a Smart Grorwbox. It is a smart box with different sensors and actuators, there objective is optimizing agricultural product by applying the various technologies. The main hardware an equipped with sensors, actuators, relays, Ethernet shield. Arduino, and routers. They developed a graphical user interface for ease the monitoring and controlling all applications that installed on the smartphone. Also, the system has two modes, the first, which is the automatic mode, it's possible to work beyond controlling from the user, and secondly, a device work necessarily with a manual mode is running in the application.

In another research, (Zaini et al.,2018), there are many types of Aquaponics systems, a Nutrient Film technique are the most popular. The principle it easy fish produce feces, and plant uses the nutrients from these feces, but if the ammonia in the feces are not controlled it well be toxic to the plant. A simple controlling of the level of ammonia, temperature, $\mathrm{pH}$ and nutrients can be easy with a smartphone mobile application applied by using the Internet of the Things (IoT) on anytime by the farmer. They prove that the device proposed can be evaluated via sensor accuracy test by small error results.

For (Mahkeswaran et al,2020), they propose an aquaponic system for the home environment, they suggestive if every family has the possibility to generate own fish and plants, the demand for food in each city and in all countries will be reduced, and specially in Singapore because of world population and climate change. The conventional method demands more land and human resources, also can't abode food security

The aquaponic system proposed are smart and sustainable, include a variety of sensors and actuators, also a microcontroller with internet connectivity for monitoring and controlling all systems.

It's based on measuring temperature water, $\mathrm{pH}$ sensor, electrical conductivity, dissolved oxygen, air temperature and humidity, light sensor and Arduino Mega 2560 microcontroller. The mobile application is created with Blynk, which is an IoT platform for hardware control and data analysis.

According to, (Tolentino et al,2019), their paper presents a greenhouse based an android device using Internet of Things (IoT), for monitoring and automatic correction with temperature -controlled

To administer the system, they include the air temperature, humidity sensor, monitoring of the $\mathrm{pH}$ level and temperature water and canopy area of plant. To attend the general objective which is the optimal system, the design was based on Arduino Mega and Raspberry Pi. They have impressive 
result in the canopy areas of the lettuce planted, compared with the conventional method. In the future, an extending study based on image processing.

To reduce using chemical treatment in plant growing, (Sansri et al.,2019), they elaborate a smart aquaponics solution (SAS), based on $\mathrm{pH}$ measure to protect the roots of plants. Using IoT to administer the lights, control humidity also develops web applications to control many parameters and storing data collected in a cloud database. The system functionate is distributed on four parties: the first step, Arduino controlled all sensors, second step: Arduino manage the equipment's on or off, third step: the data are stocked in cloud database and finally a report is showing in web application.

Aquaponics change the way that the food growing, (Uddin Butt et al.,2019), their objective was minimized the human error and maximized the crop, a mobile application for controlling by one self, so the system is double autonomous and semi-autonomous, and all data will be stored in Google Spearsheets. In the aquarium, they implement $\mathrm{pH}$ and temperature sensor, a water heater, an oxygen supplier, a water pump and a fish feeder. Also, in bed plants humidity and temperature sensor. The light bed panels. The system uses an ESP8266 microcontrollers and Relay Module, and finally the mobile application developed by Android studio, Firebase for cloud server and Google Spreadsheet to store the further analysis.

As a recapitulate, all related work cites use the based sensors, such as:

- $\mathrm{pH}$ level,

- Temperature water,

- Electrical conductivity,

- Dissolved oxygen,

- Air temperature and humidity,

- Level of ammonia,

- Light sensor

Furthermore, Arduino, Google Spreadsheet, ESP8266 microcontrollers, ThingSpeak ${ }^{\mathrm{TM}}$, Raspberry Pi, Relay Module, Firebase.

\section{Health and Economic benefits}

There are divers edges of the aquaponics system, for example generate the sufficient for urban production like fresh vegetables and fish. Essentially, if the system are involve soil-less production, so the ability from soil quality parameters, purchase a healthy production by reduce using synthetic fertilizers for the plants (pesticides and herbicides or antibiotics are acquiesce), have in the same time fish and plants and reduce the discharges in the environment (Pérez-Urrestarazu 2019).

For a healthy aquaponic environment, all elements of the system should be in the perfect rang. A specific temperature range of water, an enough water high for the dissolved oxygen content in, also a $\mathrm{pH}$ level how is another important water quality. At result aquaponic produce great vegetable quality. (Zaini 2018).

In this paragraph, the authors propose the most important health and economic factors improved by the aquaponic system: 
Figure 1. Details of smart aquaponics system

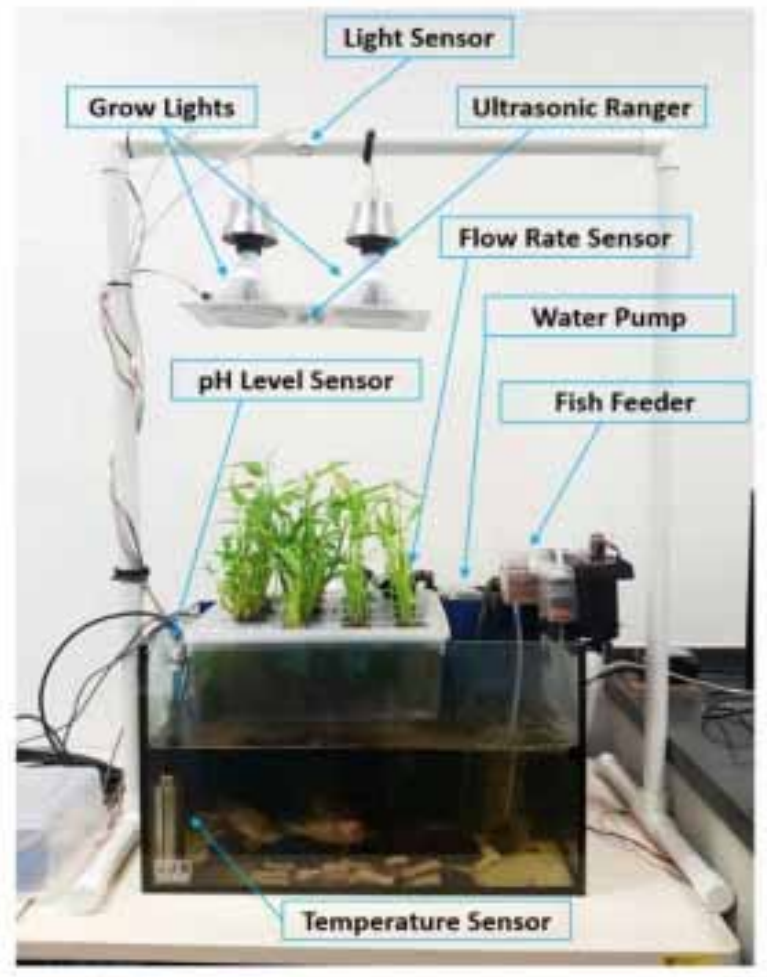

Figure 2. Example of smart aquaponics system

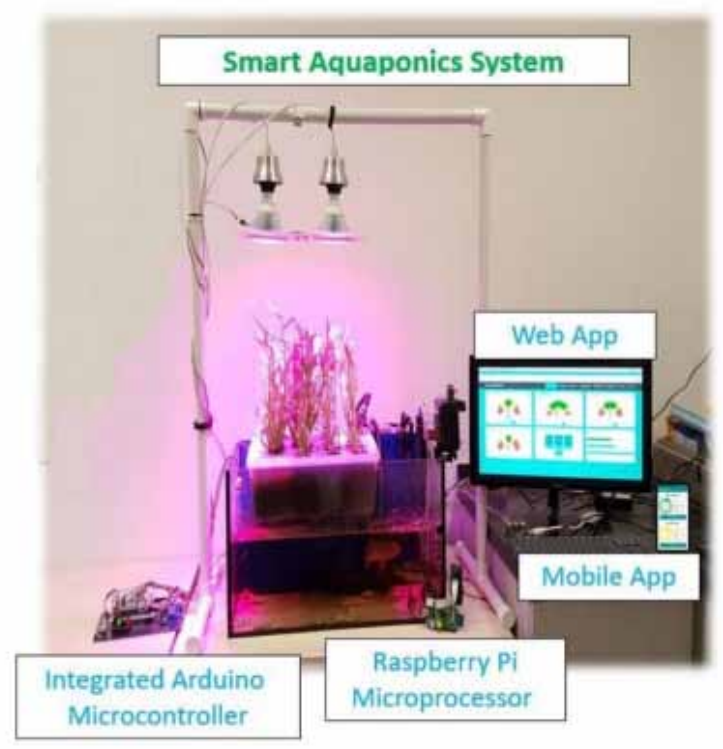

Source: https://doi.org/10.1016/j.egypro.2017.12.694 


\section{Health Benefits}

- The aquaponic system is easy to assemblage so no more hard physical effort,

- The possibility to produce more food than a traditional method (even in a per square meter),

- Recover in effort and time when we produce food by the aquaponic system,

- Forget weed and burrow and the back pain,

- Reconnect with nature and get back to basics,

- The possibility to eat one's own fish and producing vegetables in pure water and a high Food quality,

- In aquaponic system food have a taste good and get two sources of income.

Economic Benefits

- Produce more food in the small space,

- Decrease in the water used,

- Elimination of nitrogen compounds from the water sources so decrease in pollutant,

- `The waste nutrients of fish products in water are absorbed by plants so don't discharge it into the environment,

- 'Give the financial independence if the system is installing in house,

- The water is re-used via biological filtration and recirculation.

\section{OUR PROPOSITION OF AN AQUAPONIC SOLUTION BASED ON IOT TECHNOLOGIES}

Between the commercial objective and the environment, between producing more and producing better, there are several researches to find a solution that combines both, to have more productivity and protect at the same time the environment. Integrate the various IT solutions such as: IoT is an opportunity to converge towards a smart City.

Studies are different, they enrich the academic sector by proposing different points of view on the same subject. Processing information and addressing the various aspects concerning aquaponic is a high difficulty, because of different parameters and their consistency with the global system. The complexity lies in having two environments and choosing the parameters who will be in the first part of the hydroponic and the others in the aquarium having a reliable connection for the proper functioning of the system.

In this section, the authors will propose the phytotron as a solution to control the aquaponic system. Now the phytotron according to (R. Ait Abdelouahid et al., 2020), is an agricultural environmental management tool, which control the different parameters such as temperature humidity, irrigation, conductivity, $\mathrm{CO} 2$ and lighting. The idea is to bring together the impact of environmental modification and the optimization of the natural development of the plant. cloud computing and the new technologies offered by the IoT, contribute to the realization of a new phytotron tinted to produce vegetables in an urban environment.

The architecture is based on 7 parts: 


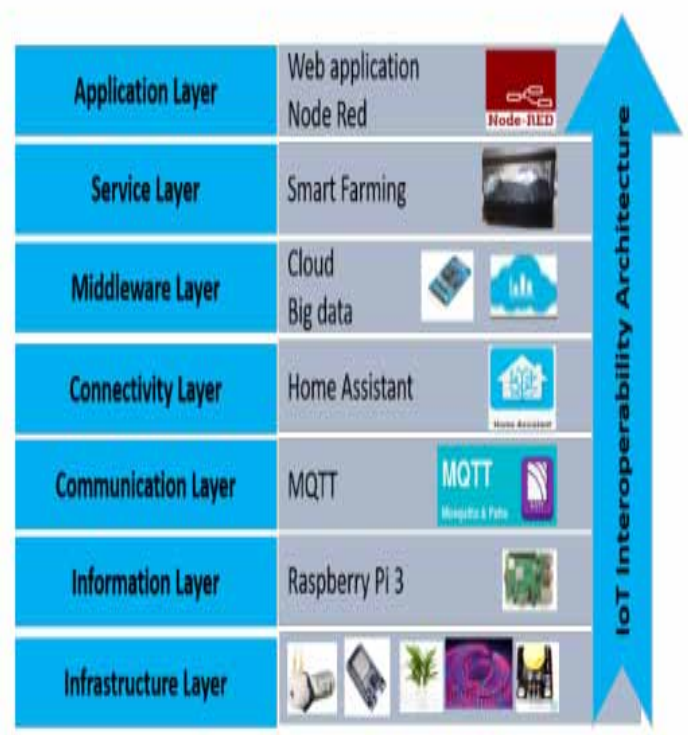

Source: "Open Phytotron: A New IoT Device for Home Gardening"

The main objective of the phytotron is controlling the artificial environment growth of the plants in order to improve the traditional method. The device is used on multiple types of hardware and interfaced with the most popular systems, for example: openHAB and home assistant, via MQTT protocol.

It is important to describe the IoT interoperability architecture, organized in the 7 layers and ensure the excellent functioning and communication between different devices. Also, the cloud architecture present in the middleware layer level.

The researches will propose an improvement of the existing phytotron, adding the parameters such as: $\mathrm{pH}$, water $\mathrm{T}^{\circ}$, water level, Air $\mathrm{T}^{\circ}$, DO, conductivity, $\mathrm{CO} 2$, etc. And presenting on $\mathrm{DO}$ dissolved oxygen and $\mathrm{pH}$ and they are inspiring the IoT Cloud ThingSpeak proposed and the architecture of predictive analytics combined with the IoT, also the information detention all related works.

The aim of this article is to propose a device that well connect different sensors and by able to interfaced with existing system such as openHAB with MQTT protocol. The physical architecture for the aquaponic solution based on IoT technologies proposed is described at the figure bellow as follow (Figure 4): 
Figure 4. Physical architecture for our Aquaponic solution based on loT technologies

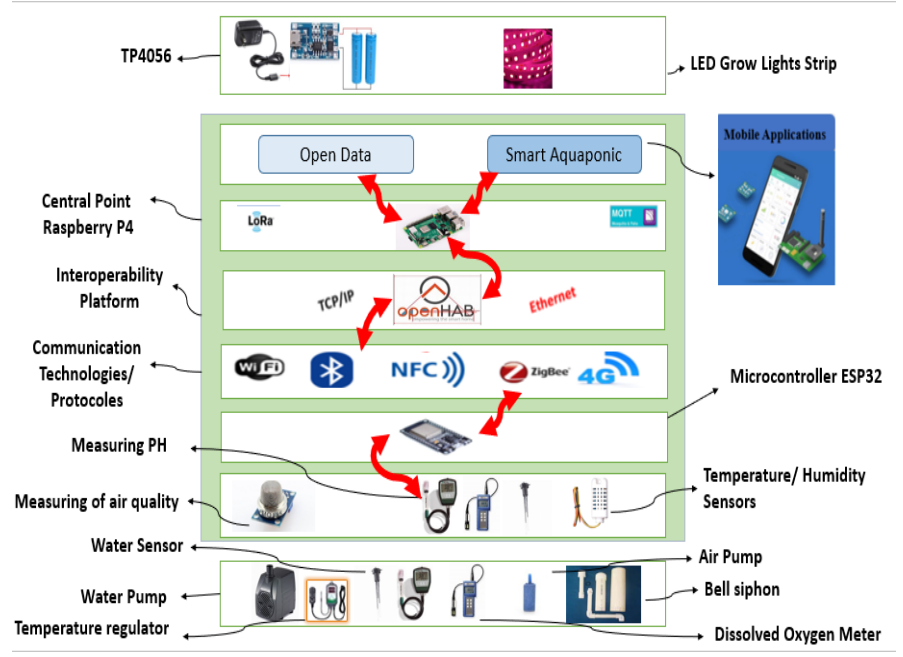

The researches will explain the main technologies proposed, beginning by the first level:

\section{First Level}

Find a Water pumps and Bell siphon, to ensure the communication between the first level and the second:

a. The Ponics Pumps PP12005 - 120 GPH Water Pump

Pump include a cage which can helps to filter out the waste existing in the water of fish, it is easy to clean filter and don't required any tools (Figure 5).

Figure 5. The Ponics Pumps PP12005 - 120 GPH Water Pump

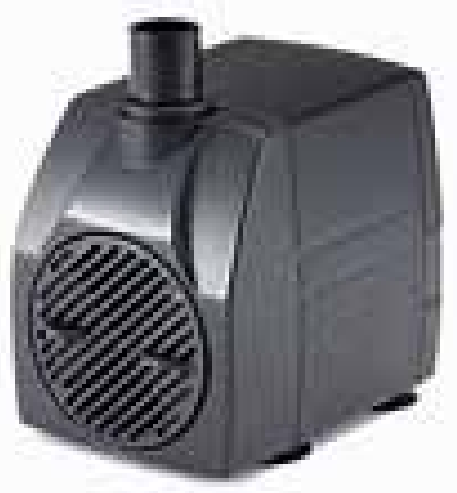

Souce:https://www.amazon.com/PonicsPumps-PP12005-Submersible-Fountains-Aquariums/ dp/B006M6MSL0 
b. Bell siphon

It required for ebb and flow aquaponic system, that represented the regulate of water Flow, for that is consider like the most important part of the system and his process repeat itself repeatedly (Figure 6).

Figure 6. The bell siphon

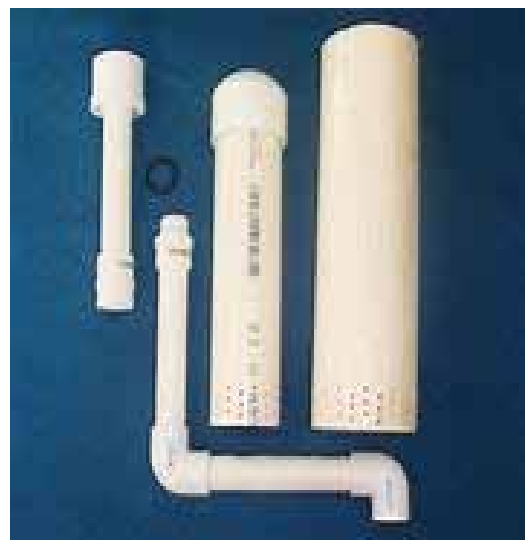

Source https://www.instructables.com/id/Make-a-Bell-Siphon/

c. Measuring $\mathrm{PH}$

In the aquaponic system plants, fish and bacteria do not have the same level of pH. Fish and bacteria are baser, plants are more acid. So, controlling the $\mathrm{pH}$ levels and balance between there is one of the most important challenges. (Figure 7).

Figure 7. pH measure

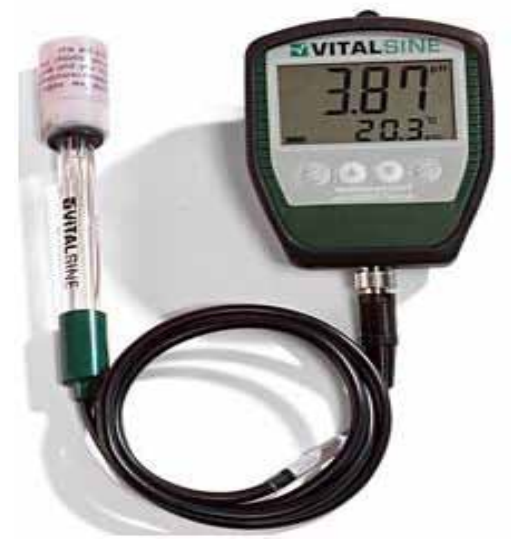


Source:The MANN 2015, https://www.friendlyaquaponics.com/2015/08/05/measuring-ph-inyour-live-aquaponic-system-water/

d. Water Sensor

Using in aquarium for detected the level of water. (Figure 8).

Figure 8. Water sensor

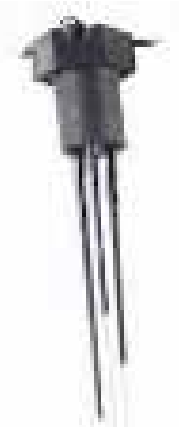

Source: https://www.olearymotorhomes.co.uk/water-sensor-probe-7-autotrail-3407-p.asp

e. Dissolved Oxygen Meter: YSI DO 200

Dissolved Oxygen Meter, Or DO indicated the level of free, non-compound oxygen in the water, it is the most important parameters to assess the quality of water. In the aquaponic system, adequate dissolved oxygen involved their continued survival. (Figure 9).

Figure 9. YSI DO 200 Dissolved Oxygen Meter

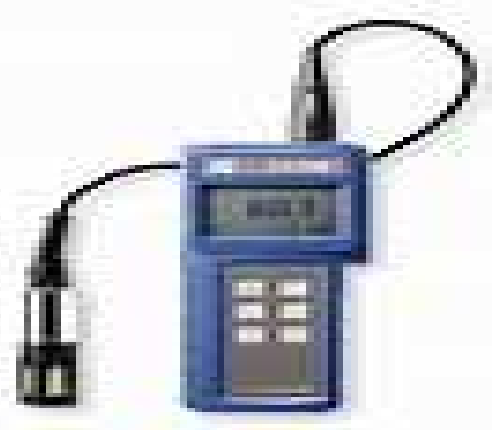


Source: https://www.amazon.com/YSI-Dissolved-Oxygen-Meter-Only/dp/B003NUYJQ0

f. The Air Pump

Connects to a small stone called a diffuser (prefer a fine bubble stone) thanks to a tube (prefer silicone tubes, ordinary plastic tubes quickly become stiff and useless). (Figure 10)

Figure 10. The Air Pump

Source: https://www.lapagedupoissonrouge.net/les-differents-parametres-de-leau-enaquariophilie/oxygenation-aquarium

g. Temperature regulator: Inkibrid ITC-308EU Wifi regulator

Heating thermostat 2 sockets heating and cooling digital thermostat with 220V.For controlling the temperature of aquaponic, a lot of options are proposed: Set maximum and minimum temperatures for this terrarium thermostat; Alarms when temperature exceeds the limit or the probe is broken; Temperature Calibration; Protection time for Refrigerator Compressor. (Figure 11).

Figure 11. inkbrid ITC-308EU Wifi temperature regulator

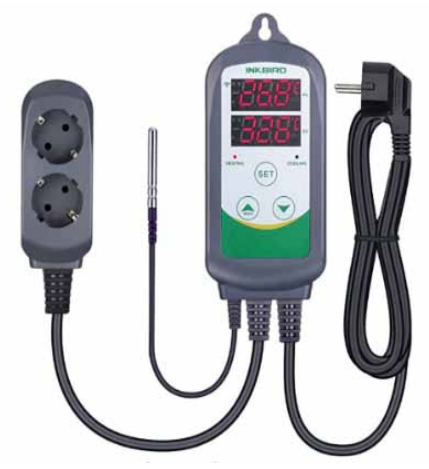

Source: https://www.ebay.fr/itm/Inkbird-ITC-308-Regulateur-De-Temperature-Thermostat-220VThermometre-Regulateur-/323761687688 


\section{Second Level}

a. Temperature/ Humidity Sensors

The AM2302 (Aosong) is a $\mathrm{I}^{2} \mathrm{C}$ sensor with a pull-up resistor of $5.1 \mathrm{Kohm}$ that objective to measures the Air temperature in Celsius degree and Relative Humidity expressed in percent (Figure 12).

Figure 12. Temperature and Humidity Digital Sensor

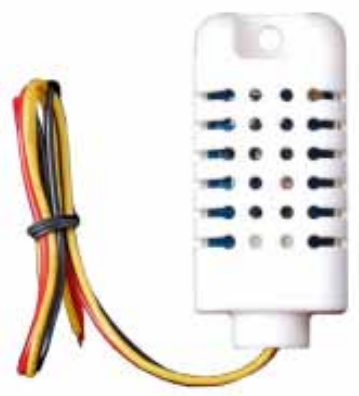

Source: https://www.arduiner.com/prodotto/dht22-am2302-modulo-digitale-sensore-misurazionetemperatura-e-umiditza/

b. Measuring of air quality MQ135

For controlling and detected the presence of pollutants in the air such us: $\mathrm{CO}, \mathrm{CO} 2, \mathrm{NH} 3$, etc. (Figure 13)

Figure 13. MQ135 measuring of air quality

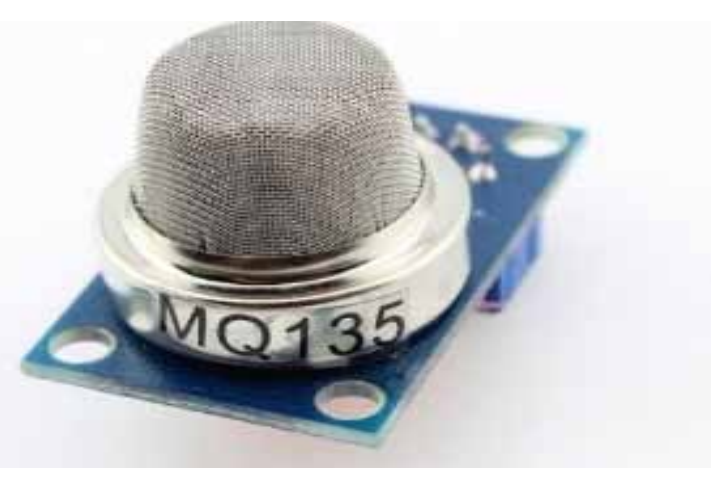

Source: https://projetsdiy.fr/mq135-mesure-qualite-air-polluant-arduino/ 
c. The TP4056

It is a complete constant-current/constant-voltage linear charger for single cell lithium-ion (LiIon) batteries. Their package and little external components make the TP4056 ideally suited for portable applications. (Figure 14).

Figure 14. TP4056- Lithium Cell Charger Module with Battery Protection

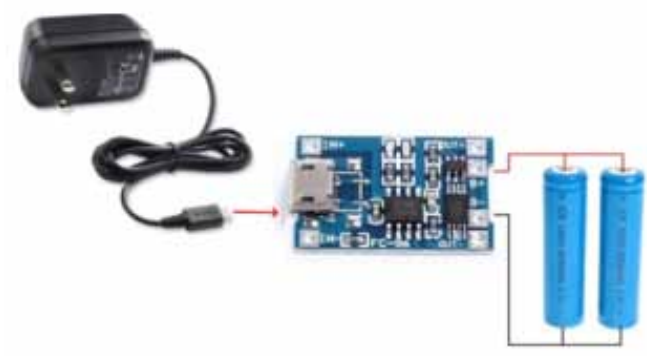

Source: https://www.amazon.fr/tp4056/s?k=tp4056

\section{d. LED Grow Lights Strip}

Have two colors composited between red and blue, and a ratio of 4:1 that is perfect to increase significantly the natural speed of grow of plants. It indicated between 15 and $30 \mathrm{~cm}$ overhead the plants. (Figure 15)

Figure 15. LED Horticultural 12V

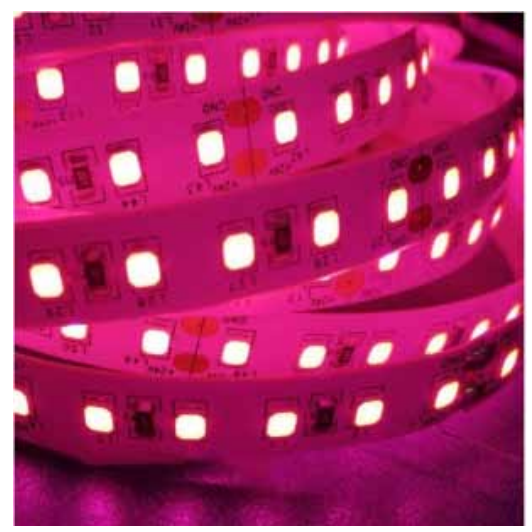

Source: https://www.inovatlantic-led.fr/rubans-led-mono/411-ruban-led-12v-horticole.html 


\section{Functioning}

Central Control System: consists in a microcontroller ESP 32 which connected with sensors and actuators, a real-time clock. the ESP-WROOM-32: is equipped with a Wi-Fi and a Bluetooth interfaces that allows it to communicate with the local gateway configurated as Access Point. We use Arduino IDE to program it in the same way as an Arduino UNO. ESP-WROOM-32 contains a Xtensa dualcore 32-bit LX6 microprocessor at $240 \mathrm{MHz}, 520 \mathrm{KiB}$ SRAM, $4 \mathrm{MiB}$ Flash Memory. Moreover, it provides 12-bit SAR ADC up to 18 channels, 2 DAC of 8-bit, 10 GPIO, 4 Serial Peripherical Interface (SPI), 2 Inter-IC Sound $\left(\mathrm{I}^{2} \mathrm{~S}\right), 2$ Inter-integrated Circuit $\left(\mathrm{I}^{2} \mathrm{C}\right)$.

The ESP32 microcontroller of our proposition publishes values of sensors on the mosquito MQTT server installed with the OpenHAB. The ESP32 subscribes also to other topics of MQTT Server to provide us with the opportunity to actuate manually the pump, the fan and lights. OpenHAB is used to visualize data sent on MQTT topics.

\section{CONCLUSION}

In this paper, the researches have described in detail a synthetic study of different existing aquaponic solutions as well as the authors have presented their proposition of a new physical architecture of an Aquaponic solution based on a general IoT interoperability architecture and a multiple IoTs technology. The aquaponic system has a lot of benefit in academic research, in the university, for example; the students have the possibility to teaching tool like mathematics, biology, chemistry and engineering, moreover, studying the interactivity between fish, plants and bacteria in a living ecosystem. Reporting the quality tests of water, (measure and track) growth rates in fish and plants also aquaponic system are used to demonstrate various principles as example, plant life cycles and their structure, sustainable farming and nitrogen cycle works. The researches plan also in the future work to provide a software architecture with a high level of interoperability that shows in details the communication between aquaponic devices and more details about indices like temperature degree, water level, $\mathrm{pH}$, DO, etc. Also the integrating of the artificial intelligence it's possible to determine the healthiness of fish and healthiness of plants, the first from movement of fish and the second from the appearance and coloring (Mahkeswaran 2020), in order to propose a prototype of an aquaponic solution for the smart campus of our university Hassan-II Casablanca, Morocco 


\section{REFERENCES}

Ait Abdelouahid, R., Chhiba, L., Marzak, A., Mamouni, A., \& Sael, N. (2017). IoT Interoperability Architectures: Comparative Study. In First International Conference on Real Time Intelligent Systems. Springer.

Ait Abdelouahid, R., \& Debauche, O. (2020). Open Phytotron: A New IoT Device for Home Gardening. 5th International Conference on Cloud Computing and Artificial Intelligence: Technologies and Applications.

Ait Abdelouahid, R., Marzak, A., \& Sael, N. (2018). Prototype models of iots interoperability. International Journal of Computer Science and Information Security, 16(3).

Ait Abdelouahid, R., Marzak, A., \& Sael, N. (2018). Towards a new metamodel of IoT Interoperability. In 2018 IEEE 5th International Congress on Information Science and Technology (CiSt) (pp. 54-63). IEEE.

Ait Abdelouahid, R., Oquaidi, M., \& Marzak, A. (2018). Towards to a New IoT Interoperability Architecture. In 2018 IEEE International Conference on Technology Management, Operations and Decisions (ICTMOD) (pp. 148-154). IEEE.

Carlos, S., Lourdes, H., \& Jimenez, D. (2018) A Brief Analysis of an Integrated Fish-Plant System through Phase Planes. IFAC, 51(13), 131-136. doi:10.1016/j.ifacol.2018.07.267

FAO (Food and Agriculture Organization of the United Nations). (2014). The State of World Fisheries and Aquaculture: Opportunities and Challenges. FAO.

Karimanzira, D., \& Rauschenbach, T. (2019). Enhancing aquaponics management with IoT-based Predictive Analytics for efficient information utilization. Information Processing in Agriculture, 6(3), 375-385. 10.1016/j. inpa.2018.12.003

Kyaw, T.-Y., \& Keong Ng, A. (2017). Smart Aquaponics System for Urban Farming Energy. Procedia, 143, 342-347. doi:10.1016/j.egypro.2017.12.694

Lee, C., \& Wang, Y-J. (2020) Development of a cloud based IoT monitoring system for Fish metabolism and activity in aquaponics. Aquacultural Engineering, 90. 10.1016/j.aquaeng.2020.102067

Mahkeswaran, R., \& Keong Ng, A. (2020). Smart and Sustainable Home Aquaponics System with Feature-Rich Internet of Things Mobile Application. 2020 6th International Conference on Control, Automation and Robotics. doi:10.1109/ICCAR49639.2020.9108041

Pérez-Urrestarazu, L., Lobillo-Eguíba, J., Fernández-Cañero, R., \& Fernández-Cabanás, V.-M. (2019). Food safety concerns in urban aquaponic production: Nitrate contents in leafy vegetables) doi:10.1016/j.ufug.2019.126431. Urban Forestry \& Urban Greening, 44(August), 126431.

Sansri, S., Hwang, W.-Y., \& Srikhumpa, T. (2019). Design and Implementaion of Smart Small Aquaponics System. 2019 Twelfth International Conference on Ubi-Media Computing (Ubi-Media). doi:10.1109/UbiMedia.2019.00071

Tolentino, Fernandez, Jorda, Amora, Bartolata, Sarucam, Sobrepeña, \& Sombol. (2019). Development of an IoT-based Aquaponics Monitoring and Correction System with Temperature-Controlled Greenhouse. 2019 International SoC Design Conference (ISOCC). doi:10.1109/ISOCC47750.2019.9027722

Vernandhes, W., Salahuddin, N., Kowanda, A., \& Sari, S. P. (2017). Smart aquaponic with monitoring and control system based on iot. 2017 Second International Conference on Informatics and Computing (ICIC). doi:10.1109/IAC.2017.8280590

Yanes, R., Martinez, P., \& Ahmad, R. (2020) Towards automated aquaponics: A review on monitoring, IoT, and smart system. Journal of Cleaner Production, 263. https://www.sciencedirect.com/science/article/pii/ S095965262031618810.1016/j.jclepro.2020.121571

Zaini, A., Kurniawan, A., \& Herdhiyanto, A.-D. (2018). Internet of Things for Monitoring and Controlling Nutrient Film Technique (NFT) Aquaponic. 2018 International Conference on Computer Engineering, Network and Intelligent Multimedia (CENIM). doi:10.1109/CENIM.2018.8711304 